\title{
Is Sorting Hat in Harry Potter Identity Identifier for Adolescents?
}

\author{
Geon Ho Bahn', Je Young Hannah Sun², Ram Hwangbo', \\ Minha Hong ${ }^{3}$, Jin Cheol Park ${ }^{4}$, and Seong Woo Cho' \\ ${ }^{1}$ Deparment of Psychiatry, Kyung Hee University School of Medicine, Seoul, Korea \\ ${ }^{2}$ Kyung Hee University School of Medicine, Seoul, Korea \\ ${ }^{3}$ Department of Psychiatry, Seonam University College of Medicine, Myongji Hospital, Goyang, Korea \\ ${ }^{4}$ Department of Psychiatry, Silverheals Hospital, Namyangju, Korea
}

\begin{abstract}
This study analyzes the role of the Sorting Hat in structuring the identity of the characters in the Harry Potter series written by J. K. Rowling. In the different stages of adolescence, one explores and re-establishes one's identity. One's sense of identity is determined by the commitments made regarding personal and social traits. However, it is difficult to establish a concrete identity formation process theory that is communicable to adolescents. In Harry Potter, the characters' identities are reflected upon the Sorting Hat and are continuously molded throughout the book. The Sorting Hat provides nurturing experiences based on temperament. Based primarily on their temperament, it sorts the students into four houses, each with their own distinct characteristics. Once sorted, the houses become the living and learning communities in which the students share the same dormitory and classes until their graduation. Within the community, the students seek connections, supportive relationships, and understanding within the group. The taking on of the group identity is an explanatory variable in the formation of individual identity. The Sorting Hat provides the students with stability and a safe boundary. After being sorted based on their temperament, the inexperienced and immature adolescents can explore different options under the guidance of the Hat before making a definite commitment. By presenting them with an appropriate environment (such as a mentor, friend, or family member), the Hat further shapes their identity and integrates the identity elements ascribed in the beginning. By providing experiences and interactions based on their unique temperament and environment, the Sorting Hat plays a crucial role in establishing the students' identities. The Sorting Hat can be an ideal model for finding one's identity during adolescence.
\end{abstract}

Key Words: Adolescent; Identity; Development; Temperament; Environment; Group.

Received: August 25, 2016 / Revision: October 15, 2016 / Accepted: November 4, 2016

Address for correspondence: Geon Ho Bahn, Department of Psychiatry, Kyung Hee University School of Medicine, 26 Kyunghee-daero, Dongdaemun-gu, Seoul 02447, Korea

Tel: +82-2-958-8556, Fax: +82-2-957-1997, E-mail: mompeian@khu.ac.kr

\section{INTRODUCTION}

Harry Potter, written by J.K. Rowling, is a chronicle and adventures of young wizards and witches. ${ }^{1)}$ Since the release of the first novel Harry Potter and the Philosopher's stone ${ }^{2)}$ on 30 June 1997, the series was the sensation of fantasy novels. The series has sold 325 million copies worldwide within 10 years of its publication of the first novel. ${ }^{3)}$ The great popularity of the series, especially among adolescents, can be explained by a presentation of psychological issues that resonates with developmental issues dominant in adolescence. ${ }^{1)}$

In addition to its entertaining literary elements, the Harry Potter series depicts characters' internal struggles and relationship with their peers and family in great details. There

This is an Open Access article distributed under the terms of the Creative Commons Attribution Non-Commercial License (http://creativecommons.org/licenses/by-nc/3.0) which permits unrestricted non-commercial use, distribution, and reproduction in any medium, provided the original work is properly cited. have been several case studies analyzing different aspects of the series and many psychoanalysts have presented interests. Our previous paper ${ }^{4}$ is also an attempt to explain the subconscious in psychoanalysis in relation to a Pensieve described in the Harry Potter series. The Pensieve is a magical object but it can be compared to electronic storing devices such as USB, CD-ROM, or R-HDD, or psychoanalytic tools such as hypnosis or eye movement desensitization and reprocessing which are also great ways to raise consciousness. Experts in brain image state different part of readers' brain is stimulated when reading a description of magic in comparison to that of mundane affairs in the Harry Potter series. ${ }^{5}$ If the readers are adolescence, along with comprehension, affective component and theory of mind, the book can affect identity formation of the readers.

Adolescence is the transitional stage from childhood to adulthood where identity formation is the main task. ${ }^{6}$ Iden- 
tity formation was proposed and systematized in Erkison's theory of personality. Erikson's theory of psychosocial development describes exploration of identity as the main task of adolescence. Along with physical changes, adolescents must prepare for transitions from childhood to adulthood. Identity development is a process of deciding who I am and what I am going to do. During the development, adolescents must go through cognitive destructuring of the old self. Identity diffusion itself is disturbing and a variety of symptoms such as confusion, mood swings, and ego-defense are observed during the transition. ${ }^{7,8)}$ Because adolescents are inexperienced and still in the search for reliable authority figures, they have not yet reached their final identity." Upon resolving the identity crisis, adolescents can move on to the next stage of the psychosocial development. Expanding on Erikson's theory of identity, Marcia ${ }^{10,11)}$ developed four identity statuses of psychological identity development. Rather than simply dividing the state into identity resolution or identity confusion, the adolescent development consists of varying degree of commitment and experiences. Individuals in identity diffusion have not yet made a commitment. Individuals in identity foreclosure have made a commitment without exploring a wide range of options. Individuals in identity moratorium are currently in a crisis and have not made a commitment. Individuals in identity achievement have successfully gone through an identity crisis. Following Erikson's and Marcia's identity formation theories are various papers explaining individuation in an effort to correspond to a real life model with greater accuracy. Expanding from 4 stages of commitment by Marcia ${ }^{11)}$ and Meeus et al. ${ }^{12)}$ proposed 7-step identity progression: 1 ) diffusion, 2) moratorium, diffusion, 3) early closure, moratorium, 4) closure, moratorium, 5) achievement, searching moratorium, 6) closure, searching moratorium, 7) achievement, early closure, 8) achievement. Pop et al. ${ }^{13)}$ showed unidirectional pattern of identity formation under academic context. Students with high academic achievement demonstrated higher level of identity commitment in comparison to those with low academic achievement. Beyers and Luyckx ${ }^{14)}$ proposed that lack of decision and commitment have negative relationship with identity formation. Since Erikson's identity formation theory, there has been a continuous effort to ameliorate the theory but no finalized form is sufficient to explain the elaborate progress of identity formation in adolescence.

The focus of this paper is on the role of the Sorting Hat in identity development of characters in Harry Potter. The Sorting Hat provides stability during identity crisis and safe boundary for characters who are inexperienced to the magic world to explore before making a commitment. By looking at the development of characters in the series, we provide an understanding of identity development in adolescence. Study of the Sorting Hat provides an accessible understanding of identity formation not only to scholars but also to adolescence and an original way of approaching the matter. Furthermore, we explore possible alternative models of the Sorting Hat in our society as well as how the society and parents exert influence in the development of the healthy identity.

\section{HARRY'S CHILDHOOD: FROM A BATTERED CHILD TO A TRUE GRYFFINDOR}

Harry Potter is an abused and neglected orphan boy, living in his maternal aunt's house. ${ }^{2)}$ His basic needs were unfulfilled. He lived in a broom closet, was often bullied by his cousin, and was withheld from meals on a regular basis. In addition to physical abuse, Harry was never emotionally nurtured by his caregivers. Aunt Petunia was envious of her little sister Lily Potter since Petunia was excluded from the magical world. Petunia's flawed relationship with Lily affected her relationship with Harry. She showered her son with gifts and let him do whatever pleased him while completely ignored Harry. Growing up in such environment, Harry felt unwanted and was in desperate need for his parents' love. There's a strong possibility that Harry developed a 'pseudo-uglyidentity' due to a deprivation of nurturing environment. On the day of his 11th birthday, Harry is invited to the mysterious world of Witchcraft and Wizardry and revealed his identity as a wizard and the history of his parents. From an orphan of no importance to a famous wizard who defeated an evil wizard, Lord Voldemort, his world turns upside down in a day. The story unravels as Harry and his closest friends, Hermione and Ron, learns friendship and bravery as they confront Lord Voldemort. However, there is more to the story than just fighting the evil. As Harry grows old, he struggles to develop and validate identity status. Among many incidences, the encounter with the Sorting Hat has great significance in the development of the characters' identity. The Hat sorts students into four houses- Gryffindor, Slytherin, Ravenclaw, and Hufflepuff, upon their acceptance to Hogwarts School of Witchcraft and Wizardry. Each house, categorized with distinct characteristics, endorses and nourishes identity development of students.

\section{IDENTITY DEVELOPMENT THEORIES DURING ADOLESCENCE}

Culture and society contribute to the development of the ego. ${ }^{15)}$ After successfully resolving crises that are distinctly social in nature, the ego grows into a mature model. Among eight distinct stages of psychosocial development, adoles- 
cents must go through identity vs. role confusion to achieve identity formation. Identity formation is a process of 'selective repudiation and mutual assimilation' of childhood identification into the newly formed configuration. ${ }^{15)}$ Often there are certain discrepancies between how community identifies the individual and the individual's way of identifying himself- in this case, Harry Potter. Because the community cannot fully understand the complexity of an individual's childhood, it forces to determine a youth's destiny within the extent that the community can. If Harry never met his family friends who understand the tragedy behind his parents' death and Harry's background or the Sorting Hat that grasps his essence, it's possible that Harry is stigmatized as a troublemaker who falls behind the school curriculum. Adolescent must establish solid realization of his identity despite the discontinuities of development itself. Marcia's ${ }^{10)}$ status model differentiates from the bipolar outcome of Erikson's identity crisis in adolescence. There are the four statuses based on the degree of exploration and commitment. The foreclosed status is characterized by strong commitment without exploration, moratorium by active exploration but no commitment, the diffused status by an absence of both commitment and exploration, and achievement by strong commitments after a process of exploration. Although the status model is based on Erikson's theory, it made attempts to describe identity formation in a perspective of development. Deprivation of his background information until Harry's 11ths birthday places Harry at the identity diffusion stage. After acceptance at Hogwarts, Harry actively explores extensive range of identities and values. Note that a commitment follows a degree of exploration. The sequence is reversed in the case of Sorting Hatthe Hat makes a commitment then the students explore to figure out the Hat's decision is legitimate. According to Erikson $^{7)}$ and Marcia, ${ }^{11}$ Harry and his friends must commit to a reintegrated sense of self through identity vs. role confusion crisis. In each series, Harry confronts his enemy, Voldemort, and based on the outcome of the challenges and exploration Harry is able to establish a sense of identity within the society. The Sorting Hat provides a perfect guideline apt to each student, minimizing the possible confusion in adolescence.

\section{THE SORTING HAT AND ITS IMPORTANCE ON THE DEVELOPMENT OF IDENTITY}

We explore the developmental significance of the Sorting Hat and possible realistic model in our society. Once admitted to Hogwarts School of Witchcraft and Wizardry, every first-grade students must go through the Sorting Ceremony. ${ }^{2)}$ Students are worried by the possibilities of being tested in front of the whole school but it is as simple as trying on the
Sorting Hat. The Sorting Hat uses Legilimency ${ }^{a}$ to interpret one's thought and interpret it. After a moment of consideration, it designates students to the houses accordingly. Four houses, Gryffindor, Slytherin, Ravenclaw, and Hufflepuff, values different traits- Gryffindor, novelty and bravery, Slytherin, power-hungry and cunning, Ravenclaw, kindness and wit, and Hufflepuff, loyalty and patience. Like family, neighborhood, school, and friends, the Sorting Hat provides contact and experimental identification with adolescence. However, unlike other environmental factors that conflict with self-aware identity, the Sorting Hat completely understands an individual and provides optimum outcome without having to fully go through the process of exploration. Arrangement to each house is a part of tentative identity formation followed by experiences and commitment to the mature identity. The houses are like family within Hogwarts in which students have classes together, sleep in the house dormitory and spend free time in the house common room. Student conduct earns or losses house points and the house with the most point is awarded the house cup. The housing system ultimately creates community sentiment and group identity.

"Oh, you may not think I'm pretty,

But don't judge on what you see,

I'll eat myself if you can find

A smarter hat than me.

You can keep your bowlers black,

Your top hats sleek and tall,

For I'm the Hogwarts Sorting Hat

And I can cap them all.

There's nothing hidden in your head

The Sorting Hat can't see,

So try me on and I will tell you

Where you ought to be.

You might belong in Gryffindor,

Where dwell the brave at heart,

Their daring, nerve, and chivalry Set Gryffindors apart;

You might belong in Hufflepuff,

Where they are just and loyal,

Those patient Hufflepuff are true And unafraid of toil;

Or yet in wise old Ravenclaw,

If you've a ready mind,

Where those of wit and learning,

Will always find their kind;

Or perhaps in Slytherin

You'll make your real friends,

Those cunning folk use any means

To achieve their ends.

a Legilimency: the act of magically navigating through many layers of a person's mind and correctly interpreting one's findings 
So put me on! Don't be afraid!

And don't get in a flap!

You're in safe hands (though I have none)

For I'm a Thinking Cap!"2)

\section{GROUP IDENTITY INFLUENCES SELF IDENTITY}

Group identity formed during school years affects the development of self-identity. ${ }^{7)}$ Mead ${ }^{16)}$ theorized how self is related to the social world. While others thought that the self was based on biological factors and inherited traits, Mead proposed 'theory of social self' in which the self emerges from social interaction. Three activities- language, play and game, develop the self. After the internalization of normative cues, standards, and social relationships of the group, the self continues to grow as it looks out for the group's interest and goals. Within his social space, the individual develops opinions, judgments, and behaviors which form a reflective conception of himself. In other words, one's identity develops as a result of interaction within a community. Especially at adolescence, a strong motivation to experience a sense of belonging and connection emerges and adolescents eagerly engage in a process of group identification. ${ }^{17)}$ The Sorting hat is more than a personality test but a conclusive factor for determining the social groups.

Plenty of rivalries exist between the houses and it's not always friendly. The rivalry is intensified by the Quidditch Cup and the House Cup. ${ }^{2)}$ Even those who are unaware of the long history of rivalry between Godric Gryffindor and Salazar Slytherin, the founders of Hogwarts, immediately respond to heated opposition. Professors favoring their own houses seem to be prevalent. Adolescents are capable of mapping such complexity of social organization. They recognize the inconsistencies or common identity between groups, ${ }^{18)}$ discriminate other groups and express personal pride in their group. ${ }^{19)}$ In many ways group affiliation and formation of the alliance to groups during adolescence have considerable effects on the formation of individual identity. Neville Longbottom is an archetypal character whose identity formation is greatly affected by the social culture of the dormitories. Neville thought he was best in Hufflepuff during his sorting. After taking a long time to decide where to put him, the Hat sent Neville to Gryffindor. At first, Neville was intimidated by Gryffindor's reputation and did not show any qualities of Gryffindor. He was introverted and rarely expressed his opinions. However, after spending many years in Gryffindor, he stood up to Draco who constantly mocked him and in his seventh year he played a crucial role in organizing and leading the Order of Phoenix, a secret society founded by Albus
Dumbledore to oppose Lord Voldemort and his Death Eaters, which required tremendous courage. Also the fact that Neville was able to draw Gryffindor's sword from the Hat, a sword that present itself to any worthy Gryffindor, to slay Voldemort's snake, Nagini, confirms that Neville established his final identity as a Gryffindor. ${ }^{20)}$

\section{TEMPERAMENTS AND CHARACTERS IN IDENTITY FORMATION}

The Sorting Hat detects promising qualities in students and sorts them in the House that would nurture their potential and put their characters to the test. The Sorting Hat's standard is very similar to several psychological tools that explore personality, such as Temperament and Character Inventory (TCI). ${ }^{21)}$ TCI is a biosocial personality model based on four temperaments (novelty seeking, harm avoidance, reward dependence, and persistence) and three characters (self-directedness, cooperativeness, and self-transcendence). Temperament is percept-based habits and skills that are heritable and manifested in early development, whereas character is a process of developing a functional relation with experiences. Novelty seeking is characterized with exploratory activity in response to novel stimulation, impulsive decision making and quick loss of temper and avoidance of frustration. ${ }^{21)}$ Such characters coincide with those of Gryffindor. Harry responses to stimuli (Voldemort) in a very reckless and impulsive manner and breaks numerous rules, believing that the end justifies the means.

Including Harry Potter, other main characters also exhibit temperaments that coincide with each house. Draco Malfoy, the quintessential Slytherin character, is intelligent and quickwitted. For instance, his father expected him to obtain top marks in his grade and Draco figured out how to use the Vanishing Cabinets in his advantages to kill Dumbledore. ${ }^{22)}$ Also, he successfully compartmentalizes his emotion as he skillfully mastered Occlumency. ${ }^{22)}$ Hufflepuff can be mistaken as bland and less talented. The House values hard work, dedication, patience and loyalty and Hufflpuffs are not as competitive as other houses which explain their poor performance in the House cup. There isn't Hufflepuff character with great importance in the series. However, Hufflepuff has produced the fewest dark wizards and they have fought against Voldemort and his forces to the very last next to Gryffindors. Next is Ravenclaw, the house of learning, wisdom and intellect. Ravenclaws are very competitive for their academic success that they backstab each other. For instance, Helena Ravenclaw, the daughter of the founder of Ravenclaw, steals her mother's Ravenclaw's Diadem to enhance her wisdom. ${ }^{20)}$ Ravenclaw also cherishes quirky and unusual 
intellectual interest. Such eccentricity can be seen in Luna Lovegood who believed in many bizarre beliefs and is a complete nonconformist. ${ }^{23)}$ By examining how environment and experiences interact with temperaments of the characters, one understands the dynamism of temperaments beyond the initial assessment given by the Sorting Hat. On its first encounter, the Hat hesitates to put Potter in Gryffindor since he exhibits strong qualities of Slytherin. The essence of Harry's Slytherin-like qualities extends beyond his initial temperament to his defense mechanism against Voldemort. Presented with impulses that are regarded unacceptable, the ego defends itself. ${ }^{24)}$

Too closely akin to his archenemy, Voldemort, Harry Potter deals with psychological conflict through projection. As he familiarizes himself in the magic world, his abilities to speak to snakes and dream about Voldemort's actions are not normal.

"A jet of green light issued from Voldemort's wand just as a jet of red light blasted from Harry's-they met in midair-and suddenly Harry's wand was vibrating as though an electric charge were surging through it; his hand seized up around it; he couldn't have released it if he'd wanted to-and a narrow beam of light connected the two wands, neither red nor green, but bright, deep gold. Harry, following the beam with his astonished gaze, saw that Voldemort's long white fingers too were gripping a wand that was shaking and vibrating."25)

Priori incantatem, a magical phenomenon that occurs when two wands with the same cores are forced to fight in a combat, shows an inevitable connection between Harry and Voldemort. ${ }^{25)}$ In each series, Harry struggles to differentiate himself from Voldemort. Voldemort and Harry do not simply share similar temperament but essentially same in essence. Harry projected his adverse qualities onto Voldemort to avoid recognizing the threatening traits in himself. When Voldemort divided his souls and hid them in seven different objects, part of his soul was embedded in Harry. To kill Voldemort, Harry has to die and be revived as his true self. Repressors defend themselves by suppressing thoughts of their undesirable traits and project this categorized traits onto other's behaviors. ${ }^{26)}$ When the Sorting Hat placed Harry in Gryffindor after a long debate, Harry struggles to extricate from a strong association with Voldemort. Only after Harry accepts his dark side and confronts with his fear can he free himself and be reborn as true Gryffindor. As Dumbledore says "It is our choices that show what we truly are, far more than our abilities"27) - the Sorting Hat analyze students by their temperament but they must make their own choices and finalize their true identity.

\section{HOW CAN WE FIND MAGIC SORTING HAT, IDENTITY IDENTIFIER IN REALITY?}

In Harry's magical world, the Sorting Hat sorts students to four houses accordingly upon their admission. During seven years of school, there hasn't been a single student who switched his house which proves that Hat's decision is correct. Unfortunately, no one in our society can predict a child's future based on his past and present. Despite the complexity of Harry's identity due to his deprived childhood and part of Voldemort's soul embedded in Harry's, the Sorting Hat precisely understands and guide Harry's development of egoidentity. It seems like temperament is the most influential factor in identity formation but the story might have been different if Harry followed the Hat's advice and went to Slytherin. Harry was influenced by other Gryffindors who allowed him to explore his ego-identity in a more stable and safe environment. This reflects great importance of environment which brings the point back to the equal importance of nature and nurture. Adolescence is a time of tremendous changes in which adolescents figure out ego-identity, experience physical changes due to hormonal excretion, and are overwhelmed by friends and academic works. ${ }^{6}$ As cognitive function develops, adolescents contemplate on their and society's future. Parents or others that try to guide adolescents who are not completely individualized and think they can solve their problems without any help can create conflicts. To know oneself takes time. Industrialization and needs for higher education also have lengthened the adolescence and made it more difficult to establish the identity. ${ }^{28)}$ Excessive competition rather results in social regression and creates social phenomenon like hikikomori among those with shy personality or life experiences like rejection by peers and parents. ${ }^{29)}$ In the past people believed hikikomori was a social phenomenon exclusive to the Japanese culture but the similar phenomenon is seen in Korea, India, and the United States. ${ }^{30)}$ Because the standard for ego-identity have become more diverse as the society becomes more complex, ${ }^{31)}$ it is advisable to believe in children's natural temperament and wait patiently for them to find their true identity despite how many trial and error. ${ }^{32)}$ One must intervene only when children can't figure out by themselves. Harry's case is exceptional in that he spent deprived childhood and then acquired enormous support in his adolescence. The establishment of an affectionate relationship with parents and children is ideal to minimize mistakes in adolescents. The parents cannot be the Sorting Hat when the children are going through early closure, moratorium or identity diffusion, but, they can at least trust their decision and express support. 


\section{CONCLUSION}

How is identity established during adolescence? In the magic world, even after the Sorting Hat assigned Harry to Gryffindor, he has experienced many conflicts to re-establish his identity. Harry had to accept the fact that his death is the only way to remove Voldemort. In the final battle between Harry and Voldemort, his friends, family, and teacher fight at the risk of their lives. The battle does not just represent good vs. evil but also a commitment to each character's identity. And presentation of the sword of Gryffindor to both Harry and Neville confirms overcoming of identity diffusion and commitment to the final identity.

In reality, conflicts between children and their parents aggravate as they become adolescents. Children must adapt to the transformation of both body image and emotional changes and the instability can be enunciated as hatred or complaints toward their parents. Adolescence can be a strenuous time even for parents with an affectionate relationship with their children. Because adolescence is such a turbulent period in life, it is important that parents, school environments, and the society be available as the Sorting Hat for the adolescents to develop their own identity. While adolescence must be resilient in the face of adversity, the society and others must be prepared to carry out the role of Sorting Hat in the time of need.

\section{Conflicts of Interest}

The authors have no financial conflicts of interest.

\section{REFERENCES}

1) Rosegrant J. The deathly hallows: Harry Potter and adolescent development. J Am Psychoanal Assoc 2009;57:1401-1423.

2) Rowling JK. Harry Potter and the Philosopher's stone. London: Bloomsbury Publishing; 1997.

3) Blake A. The irresistible rise of Harry Potter. London/New York: Verso;2002.

4) Lee SY, Moon DS, Chung US, Bahn GH. Harry Potter's Pensieve and the unconscious. Psychoanalysis 2013;24:92-101.

5) Hsu CT, Jacobs AM, Citron FM, Conrad M. The emotion potential of words and passages in reading Harry Potter--an fMRI study. Brain Lang 2015;142:96-114.

6) Bahn GH, Ryu JE, Lee YJ, Han J, Lee A, Hong M. When Is the endpoint of the adolescence? Psychoanalysis 2015;26:3-17.

7) Erikson EH. Identity, youth, and crisis. New York: W.W. Norton and Company, Inc.;1968.

8) Erikson EH. The problem of ego identity. J Am Psychoanal Assoc 1956;4:56-121.

9) Buescher TM. A framework for understanding the social and emotional development of gifted and talented adolescents. Roeper Review 1985;8:10-15.

10) Marcia JE. Development and validation of ego-identity status. J Pers
Soc Psychol 1966;3:551-558.

11) Marcia JE. Identity in Adolescence. In: Adelson J, editor. Handbook of adolescent psychology. New York: John Wiley and Sons;1980. p.159-187.

12) Meeus W, van de Schoot R, Keijsers L, Schwartz SJ, Branje S. On the progression and stability of adolescent identity formation: a five-wave longitudinal study in early-to-middle and middle-to-late adolescence. Child Dev 2010;81:1565-1581.

13) Pop EI, Negru-Subtirica O, Crocetti E, Opre A, Meeus W. On the interplay between academic achievement and educational identity: a longitudinal study. J Adolesc 2016;47:135-144.

14) Beyers W, Luyckx K. Ruminative exploration and reconsideration of commitment as risk factors for suboptimal identity development in adolescence and emerging adulthood. J Adolesc 2016;47:169-178.

15) Erikson EH. Identity and the life cycle. New York: W.W. Norton and Company, Inc.;1959.

16) Mead GH. Mind, self and society: from the standpoint of a social behaviorist. Chicago: University of Chicago Press;1934.

17) Hoge DR, McCarthy JD. Influence of individual and group identity salience in the global self-esteem of youth. J Pers Soc Psychol 1984;47:403-414.

18) Prentice DA, Miller DT, Lightdale JR. Asymmetries in attachments to groups and to their members - distinguishing between commonidentity and common-bond groups. Personality and Social Psychology Bulletin 1994;20:484-493.

19) Valk A. Ethnic identity, ethnic attitudes, self-esteem, and esteem toward others among Estonian and Russian adolescents. J Adolesc Res 2000;15:637-651.

20) Rowling JK. Harry Potter and the deathly hallows. London: Bloomsbury Publishing;2007.

21) Cloninger CR, Svrakic DM, Przybeck TR. A psychobiological model of temperament and character. Arch Gen Psychiatry 1993;50: 975-990.

22) Rowling JK. Harry Potter and the half-blood prince. London: Bloomsbury Publishing;2005.

23) Rowling JK. Harry Potter and the order of the phoenix. London: Bloomsbury Publishing;2003.

24) Freud A. The ego and the mechanisms of defense [The writings of Anna Freud, volume II 1936]. New York: Internatiional Universities Press; 1966.

25) Rowling JK. Harry Potter and the goblet of fire. London: Bloomsbury Publishing;2000.

26) Newman LS, Duff KJ, Baumeister RF. A new look at defensive projection: thought suppression, accessibility, and biased person perception. J Pers Soc Psychol 1997;72:980-1001.

27) Rowling JK. Harry Potter and the chamber of secrets. London: Bloomsbury Publishing; 1998.

28) Arnett JJ. G. Stanley Hall's adolescence: brilliance and nonsense. Hist Psychol 2006;9:186-197.

29) Teo AR, Gaw AC. Hikikomori, a Japanese culture-bound syndrome of social withdrawal?: a proposal for DSM-5. J Nerv Ment Dis 2010; 198:444-449.

30) Teo AR, Fetters MD, Stufflebam K, Tateno M, Balhara Y, Choi TY, et al. Identification of the hikikomori syndrome of social withdrawal: psychosocial features and treatment preferences in four countries. Int J Soc Psychiatry 2015;61:64-72.

31) Rothe EM, Tzuang D, Pumariega AJ. Acculturation, development, and adaptation. Child Adolesc Psychiatr Clin N Am 2010;19:681-696.

32) Bester G, Marais AC. The phenomenon of adolescents placing pressure on their parents. J Child Adolesc Ment Health 2014;26:15-33. 